Abstracta Iranica

Revue bibliographique pour le domaine irano-aryen

Volume 32-33 | 2013

Comptes rendus des publications de 2009-2010

\title{
Almut Hintze. The Cow that Came from the Moon: the Avestan Expression māh-gaociora-
}

\section{Mihaela Timus}

\section{(2) OpenEdition}

\section{Journals}

\section{Édition électronique}

URL : http://journals.openedition.org/abstractairanica/40117

DOI : 10.4000/abstractairanica.40117

ISSN : 1961-960X

Éditeur :

CNRS (UMR 7528 Mondes iraniens et indiens), Éditions de l'IFRI

\section{Édition imprimée}

Date de publication : 1 décembre 2013

ISSN : 0240-8910

\section{Référence électronique}

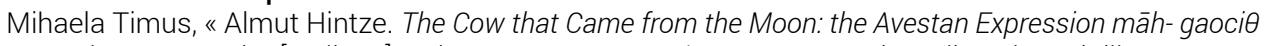
ra- », Abstracta Iranica [En ligne], Volume 32-33 | 2013, document 12, mis en ligne le 01 juillet 2016, consulté le 26 septembre 2020. URL : http://journals.openedition.org/abstractairanica/40117 ; DOI : https://doi.org/10.4000/abstractairanica.40117

Ce document a été généré automatiquement le 26 septembre 2020.

Tous droits réservés 


\title{
Almut Hintze. The Cow that Came from the Moon: the Avestan Expression māh-gaociӨra-
}

\author{
Mihaela Timus
}

\section{RÉFÉRENCE}

"The Cow that Came from the Moon: the Avestan Expression māh-gaociora-», in : C. A. Bromberg, N. Sims-Williams, U. Sims-Williams, eds., BAI: Iranian and Zoroastrian Studies in Honor of Prods Oktor Skjervø, vol. 19, 2005 [2009], Detroit (Michigan), Iowa State University Press, 2009, p. 57-66.

1 L'ouverture de l'article comporte un index assez riche de choix de traductions

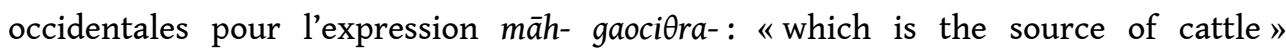
(Bartholomae 1904); «the moon which has the bull's seed» (Panaino 2005), «la lune qui a la vache comme marque distinctive» (Kellens 2006), aussi bien que pour l'av. čitra-, avec ses deux champs sémantiques majeurs: 1. «manifest, visible, clear, appearance »; 2. «seed, origin, descent» (voir Bartholomae, Duchesne-Guillemin, Soudavar).

2 Le noyau de la contribution est constitué par la comparaison entre l'uranographie et la cosmographie du Rašn Yašt (RY), d'une part, et le récit de la création fourni par le Bundahišn ( $B d$. ), d'une autre part. Les deux spécimens de littérature (avestique et pehlevi) comportent chacune une partition ternaire (étoiles, lune, soleil) du ciel. Si la progression du récit avestique est ascendante (de bas en haut), le récit pehlevi présente les choses dans l'ordre inverse. Dans les deux cas, le vecteur entre l'uranographie et la cosmogonie est donné par une vision mythologique : le čitra-/čihr des éléments de la création se retrouve dans un des trois registres du ciel. En rajoutant le constat que le genre de l'homme primordial Gayōmard est masculin, alors que celui de l'animal (tant singulier/primordial que multiplié en espèces) est féminin, l'A. parvient à la conclusion 


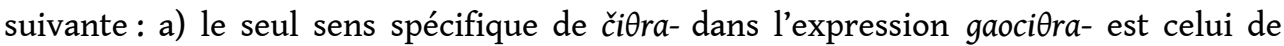
«semence, origine»; b) il doit y avoir eu un mythe avestique selon lequel la race humaine et les animaux procédaient d'un seul prototype ; c) le mythe pehlevi du čihr des créations (Bd.) est certainement enraciné dans l'Avesta.

\section{AUTEURS}

\section{MIHAELA TIMUS}

Institut d'Histoire des Religions, Bucarest 